\title{
Modality and variability as factors in training the elderly
}

Citation for published version (APA):

van Gerven, P. W. M., Paas, F., van Merrienboer, J. J. G., \& Schmidt, H. G. (2006). Modality and variability as factors in training the elderly. Applied Cognitive Psychology, 20, 311-320.

https://doi.org/10.1002/acp.1247

Document status and date:

Published: 01/01/2006

DOI:

10.1002/acp.1247

Document Version:

Publisher's PDF, also known as Version of record

Document license:

Taverne

Please check the document version of this publication:

- A submitted manuscript is the version of the article upon submission and before peer-review. There can be important differences between the submitted version and the official published version of record.

People interested in the research are advised to contact the author for the final version of the publication, or visit the DOI to the publisher's website.

- The final author version and the galley proof are versions of the publication after peer review.

- The final published version features the final layout of the paper including the volume, issue and page numbers.

Link to publication

\footnotetext{
General rights rights.

- You may freely distribute the URL identifying the publication in the public portal. please follow below link for the End User Agreement:

www.umlib.nl/taverne-license

Take down policy

If you believe that this document breaches copyright please contact us at:

repository@maastrichtuniversity.nl

providing details and we will investigate your claim.
}

Copyright and moral rights for the publications made accessible in the public portal are retained by the authors and/or other copyright owners and it is a condition of accessing publications that users recognise and abide by the legal requirements associated with these

- Users may download and print one copy of any publication from the public portal for the purpose of private study or research.

- You may not further distribute the material or use it for any profit-making activity or commercial gain

If the publication is distributed under the terms of Article $25 \mathrm{fa}$ of the Dutch Copyright Act, indicated by the "Taverne" license above, 


\title{
Modality and Variability as Factors in Training the Elderly
}

\author{
PASCAL W. M. VAN GERVEN ${ }^{1 *}$, FRED PAAS $^{2,3}$, \\ JEROEN J. G. VAN MERRIËNBOER ${ }^{2}$ and HENK G. SCHMIDT ${ }^{3}$ \\ ${ }^{1}$ Department of Neurocognition, Faculty of Psychology, Maastricht University, The Netherlands \\ ${ }^{2}$ Educational Technology Expertise Center (OTEC), Open University of The Netherlands, \\ The Netherlands \\ ${ }^{3}$ Institute of Psychology, Faculty of Social Sciences, Erasmus University Rotterdam, \\ The Netherlands
}

\begin{abstract}
SUMMARY
Cognitive load theory (CLT) predicts that bimodal processing of instructional material decreases the level of extraneous cognitive load, whereas increased training variability increases the level of germane cognitive load. It was hypothesized that a combination of these strategies leads to optimal learning, especially in older adults. Forty young and forty elderly learners were trained to solve complex problems. The results showed that bimodal training leads to lower cognitive load than unimodal training. Furthermore, random presentation of examples (high variability) led to higher performance than blocked presentation (low variability) in both age groups. However, there was no combined effect of modality and variability. Moreover, the elderly did not take disproportionate advantage of the bimodal and random conditions. It was concluded that these training methods bear important potential in the light of lifelong learning. Copyright (C) 2006 John Wiley \& Sons, Ltd.
\end{abstract}

Acquiring complex cognitive skills makes high demands on working memory. These demands are not only determined by the complexity of the skill, but also by the format of training. Basically, training can stimulate two types of processing: relevant processing, which directly contributes to the learning process, and irrelevant processing, which impedes the learning process. Thus, training should be designed in such a way that it leads to maximal relevant and minimal irrelevant processing. This principle is propagated by cognitive load theory (CLT) (Sweller, van Merriënboer, \& Paas, 1998; van Merriënboer \& Sweller, 2005). CLT was developed from the notion that although working memory is capable of processing complex material, it is vulnerable to overload, which leads to poor comprehension and obstructs learning. A combination of reduced irrelevant or extraneous cognitive load, and optimized relevant, or germane cognitive load should therefore lead to an optimal construction of cognitive schemata (e.g. van Merriënboer, Schuurman, De Croock, \& Paas, 2002), which enable a learner to achieve enhanced transfer performance (Paas \& van Merriënboer, 1994a).

\footnotetext{
*Correspondence to: Pascal W. M. van Gerven, Department of Neurocognition, Faculty of Psychology, Maastricht University, P.O. Box 616, 6200 MD Maastricht, The Netherlands. E-mail: p.vangerven@psychology.unimaas.nl.

Contract/grant sponsor: Netherlands Organization for Scientific Research (NWO).
}

Copyright (C) 2006 John Wiley \& Sons, Ltd. 
The philosophy of CLT seems especially applicable in cases where working-memory capacity is particularly limited, such as in the elderly (Paas, Camp, \& Rikers, 2001; van Gerven, Paas, van Merriënboer, \& Schmidt, 2000). It is long established that elderly people have to cope with a decline of working memory. Basically, this results in a decrease of the capacity to process information (e.g. Salthouse \& Babcock, 1991). Furthermore, there is a general decrease of processing speed (e.g. Salthouse, 1996) and a reduced ability to inhibit irrelevant information (e.g. Hasher \& Zacks, 1988). Finally, there is a decline in the ability to coordinate interrelated task processes (e.g. Mayr, Kliegl, \& Krampe, 1996). These declines have a substantial impact on the elderly's ability to process and store new information. Theoretically, CLT-based training formats can compensate for these agerelated cognitive declines (van Gerven et al., 2000). That is, reducing extraneous processing and maximizing germane processing is expected to lead to an optimal use of available cognitive resources.

With respect to the reduction of extraneous cognitive load, this study will focus on the so-called modality effect, which shows that addressing both the visual and auditory modality leads to better learning than merely addressing the visual modality (Kalyuga, Chandler, \& Sweller, 2000; Moreno \& Mayer, 1999; Tabbers, Martens, \& van Merriënboer, 2004; Tindall-Ford, Chandler, \& Sweller, 1997). This effect is explained by the assumption that working memory consists of two modality-specific components, each of which has a limited capacity (Baddeley, 1992). Thus, if textual material is presented through the auditory instead of the visual modality, then less load is imposed on the visual store and chances of overload are reduced. Although previous research on the modality effect in elderly learners is limited (e.g. van Gerven, Paas, van Merriënboer, Hendriks, \& Schmidt, 2003), beneficial effects of audiovisual stimulus presentation on learning in elderly individuals have been observed outside the educational research realm (e.g. Constantinidou \& Baker, 2002).

If extraneous cognitive load is reduced, more capacity becomes available for germane cognitive load in working memory. One way to optimize the level of germane cognitive load is to increase training variability (Olina, Reiser, Huang, Lim, \& Park, 2006; Paas \& van Merriënboer, 1994b; Renkl, Stark, Gruber, \& Mandl, 1998; van Merriënboer et al., 2002). This can be achieved by presenting training problems of different categories in a random order, instead of clustering them in blocks of the same category. High training variability leads to contextual interference (Battig, 1972), which prevents learners from superficial processing of individual training problems. Instead, learners are compelled to reexamine every new training problem, which leads to deeper processing and thus higher levels of germane cognitive load (De Croock, van Merriënboer, \& Paas, 1998). Jamieson and Rogers (2000) are among the few who found beneficial effects of training variability in older adults. Based on research showing that elderly people experience more difficulty with task switching (e.g. Salthouse, Fristoe, McGuthry, \& Hambrick, 1998), these authors expected the elderly to have more difficulty with a high variability or random training schedule. They found, however, that older adults take as much advantage of random practice as younger adults. At the same time, their data suggest that the elderly participants had to invest more mental effort during random training than the young.

The first aim of the current study was to compensate possible age-related differences in required mental effort by reducing the amount of extraneous cognitive load. Because this will spare a relatively large portion of cognitive resources in the elderly, they may take even more advantage of a random practice schedule than the young (see van Gerven et al., 2000). Extraneous load was manipulated by varying the modality of the training problems. These 
were presented in a worked-out fashion: images of problem states were accompanied by explanatory text. In a unimodal condition, the text was presented visually. In a bimodal condition, the text was presented auditorily.

A second aim of this study was to increase germane cognitive load by varying the variability of the training problems. In a blocked sequence (i.e. low variability), training problems were presented in blocks of the same category, for example: C1P1, C1P2, C1P3, $\mathrm{C} 2 \mathrm{P} 1, \mathrm{C} 2 \mathrm{P} 2, \mathrm{C} 2 \mathrm{P} 3$, in which $\mathrm{C}$ stands for the problem category and $\mathrm{P}$ for an individual training problem. In a random sequence (i.e. high variability), on the other hand, problems of different categories were intermixed, for example: C2P3, C1P2, C1P1, C2P2, C1P3, C2P1.

It was hypothesized that bimodal worked examples would lead to lower levels of cognitive load than unimodal worked examples. Furthermore, it was hypothesized that worked examples would lead to higher levels of cognitive load if they are randomly sequenced than if they are sequenced in blocks. At the same time, however, this higher training variability was expected to lead to higher transfer performance. The elderly participants, finally, were expected to show higher cognitive load and lower performance than the young participants, but to take more advantage of the bimodal and random conditions.

\section{METHOD}

\section{Participants}

Forty students (10 men and 30 women, mean age $=23.3$ years, $S D=3.0$ ) of Maastricht University represented the young group. Forty older adults (24 men and 16 women, mean age $=65.1$ years, $S D=4.5$ ), who were recruited via advertisements in local newspapers, represented the old group. All participants were in good health and had normal or corrected-to-normal vision. They received $€ 16$ for their participation.

On a shortened version of the Groningen Intelligence Test (GIT; Luteijn \& Van der Ploeg, 1983), the older participants scored significantly higher $\left(M_{\mathrm{IQ}}=126.6 ; S D=11.4\right)$ than their young counterparts $\left(M_{\mathrm{IQ}}=120.9, S D=7.7\right), t(78)=-5.73, p=0.01$. In contrast, working memory performance, as measured by Salthouse and Babcock's (1991) computation-span test, was significantly lower in the elderly $M_{\text {span }}=3.5 ; S D=1.3$ ) than in the young $\left(M_{\text {span }}=5.3 ; S D=1.3\right), t(78)=6.34, p<0.001$.

\section{Subjective cognitive-load scale}

A nine-point symmetrical category scale was used as a subjective cognitive-load (SCL) measure (after Paas, van Merriënboer, \& Adam, 1994). The scale was presented in Dutch on a touch screen and accompanied by the phrase: I have experienced the foregoing as: ... The scale had three labels, ranging from not difficult at all (1), via moderately difficult (5), to very difficult (9). Intermediate values were not labelled. Paas (1992) and Paas and van Merriënboer (1994b) found internal consistency coefficients (Cronbach's $\alpha$ ) of 0.90 and 0.82 , respectively, using comparable scales. Paas, Tuovinen, Tabbers, and van Gerven (2003) evaluated the scale as a highly reliable and sensitive instrument for assessing cognitive load.

\section{Secondary task}

In addition to the SCL scale, a secondary-task paradigm was used to measure cognitive load. The idea behind this method is that higher response times on the secondary task 
reflect higher levels of cognitive load. Although the secondary-task paradigm provides a relatively objective and accurate picture of general cognitive load, it is not a frequently used technique in CLT research (exceptions are Chandler \& Sweller, 1996; Marcus, Cooper, \& Sweller, 1996; Sweller, 1988). Participants had to detect the random illumination of a large jukebox button (approximately $2 \times 2$ in.) on a response box, which was placed in front of the presentation display. The software controlling the illumination of the button and the registration of the reaction times (in $\mathrm{ms}$ ) was programmed in Experimental Run Time System (ERTS; BeriSoft, Frankfurt, Germany).

\section{Problem domain}

A computerized version of Luchins' (1942) water-jug problem was selected as the problem domain. The water-jug task required the participant to obtain a certain amount of water in a target jug by pouring jugs of different sizes and filled with varying amounts of water into each other. The key rule was that jugs could not overflow. If water was poured from one jug into another, and the contents of the donating jug exceeded the free space of the receiving jug, pouring stopped as soon as the receiving jug was full. In that case a residual remained in the donating jug. In some cases, this residual equaled the desired amount of water. In other cases it could be used for further operations.

The software controlling the water-jug task was programmed in Authorware 3.5 (Macromedia, San Francisco). The interaction with the computer took place through a Philips Brilliance 107 17-in. display with an integrated touch screen (Elo TouchSystems, Fremont, CA). For a brief explanation of the interface, see Figure 1.

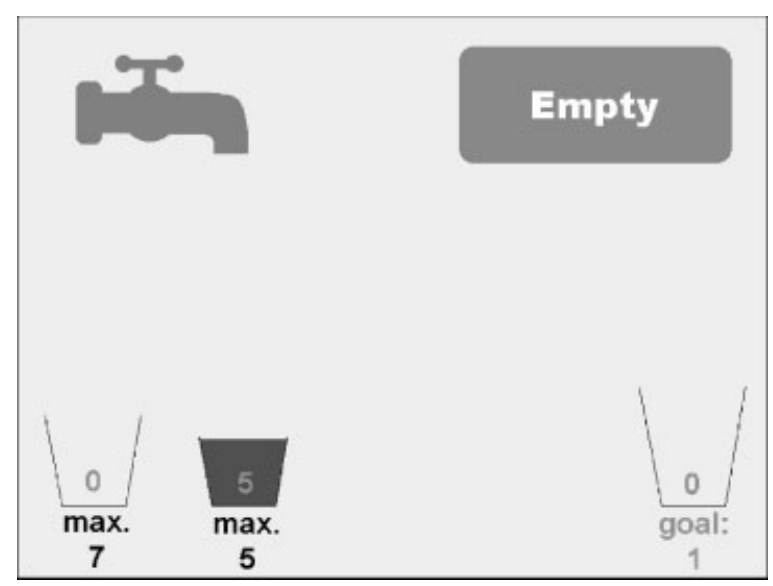

Figure 1. Interface of the water-jug task as it was displayed on the touch screen. A variable number of working jugs (two to four) were depicted in the lower left corner of the display. The current contents were superimposed on the jugs. The maximum capacity was displayed beneath the jugs. The target jug was depicted in the lower right corner of the display. The goal amount of water was displayed beneath the target jug. Each jug — except for the target jug — could be filled with water by successively touching the tap and the jug. A jug —including the target jug — could be emptied by successively touching the 'Empty' button and the jug. Jugs could be poured into each other by first touching the donating jug and then the receiving jug (which could also be the target jug) 


\section{Training problems}

Ten water-jug problems were selected as training material by presenting them as workedout examples. There were five problem categories and two worked examples per category. Categories included 'summation' of jugs, 'subtraction' of jugs, a combination of summation and subtraction, and two categories of repeated subtraction (see van Gerven, 2002, for a more detailed description).

\section{Transfer test}

The transfer test consisted of 12 water-jug problems, which were arranged by increasing complexity, that is, from near transfer, requiring basic strategies, to far transfer, requiring a combination of basic strategies.

\section{Design and procedure}

There were three independent variables: age group (young, old), modality (unimodal, bimodal), and variability (blocked, random), which resulted in a $2 \times 2 \times 2$ between subjects design. Ten young and ten older participants were randomly assigned to each of the four experimental conditions. Dependent variables were subjective cognitive load (SCL) during training, reaction time during training, and performance (the proportion of solved test problems).

The experiment took place in individual sessions. During training, worked examples were presented as a sequence of full-screen images representing the solution steps. Consistent with Tabbers et al. (2004), it was decided to make this presentation computer paced. In the unimodal condition, explanatory text (Dutch) was imposed on the images. In the bimodal condition, the images were accompanied by an auditory version of the same text (recorded by a Dutch-speaking female). The time intervals between the pictures were based on the duration of the narrations in the bimodal condition. In the blocked condition, worked examples of the same category were presented in blocks of two. The order of the five blocks (one per category) was counterbalanced by applying a $5 \times 5$ Latin square. In the high-variability condition, the order of the problems was randomized such that problems of the same category did not follow each other.

During each worked example, the response button for the secondary task was illuminated three times at random time intervals. Illumination was extinguished as soon as the participant pushed the button or else after $2000 \mathrm{~ms}$. After each worked example, the participant was requested to rate his or her perceived level of cognitive load (SCL).

After the training session, the transfer test was administered. There was a time limit of 6 minutes per problem. The participants had the possibility to skip problems on request. They rarely made use of this option, however.

\section{RESULTS}

A $2 \times 2 \times 2$ between-subjects analysis of variance (ANOVA) was performed on all dependent measures. The means and standard deviations of the dependent measures are summarized in Table 1. 
Table 1. Means and standard deviations of the dependent measures

\begin{tabular}{|c|c|c|c|c|c|c|}
\hline & & & \multicolumn{2}{|c|}{ Blocked } & \multicolumn{2}{|c|}{ Random } \\
\hline & & & $M$ & $S D$ & $M$ & $S D$ \\
\hline \multirow[t]{6}{*}{ Young } & \multirow[t]{3}{*}{ Unimodal } & SCL & 2.5 & 1.5 & 2.1 & 1.0 \\
\hline & & Reaction time & 550 & 110 & 634 & 217 \\
\hline & & Performance & 0.84 & 0.13 & 0.89 & 0.11 \\
\hline & \multirow[t]{3}{*}{ Bimodal } & SCL & 1.6 & 0.6 & 1.7 & 0.5 \\
\hline & & Reaction time & 582 & 201 & 564 & 251 \\
\hline & & Performance & 0.82 & 0.19 & 0.87 & 0.20 \\
\hline \multirow[t]{6}{*}{ Old } & \multirow[t]{3}{*}{ Unimodal } & SCL & 2.8 & 1.7 & 3.2 & 2.1 \\
\hline & & Reaction time & 822 & 156 & 810 & 275 \\
\hline & & Performance & 0.46 & 0.27 & 0.61 & 0.22 \\
\hline & \multirow[t]{3}{*}{ Bimodal } & SCL & 1.8 & 1.2 & 2.4 & 1.2 \\
\hline & & Reaction time & 704 & 219 & 734 & 173 \\
\hline & & Performance & 0.52 & 0.17 & 0.57 & 0.26 \\
\hline
\end{tabular}

Note: $\mathrm{SCL}=$ Subjective Cognitive Load.

\section{Subjective cognitive load}

With regard to SCL, the ANOVA yielded a main effect of age group, $F(1,72)=4.02$, $\mathrm{MSE}=1.7, p<0.05$. Furthermore, there was a main effect of modality, $F(1,72)=7.05$, $p=0.01$. That is, higher levels of SCL were reported in the unimodal condition $(M=2.6$, $S D=1.6)$ than in the bimodal condition $(M=1.9, S D=1.0)$. The effect was rather small, however (see Figure 2(A)). The factor variability did not yield a significant effect $(F<1)$. None of the possible interactions between age group, modality, and variability were significant $(F \mathrm{~S}<1.5)$. This means that there was no combined effect of modality and variability. Furthermore, the elderly did not take disproportionate advantage of the bimodal and random conditions.

\section{Reaction time on the secondary task}

A modest correlation $(r=0.31, p<0.01)$ was found between reaction time on the secondary task and SCL, which suggests that these measures partially reflect the same aspects of cognitive load, but at the same time may complement each other. The reaction times revealed a pattern that slightly deviates from the subjective load measures (see Figure 2(B)). There was a significant effect of age group, $F(1,72)=16.08, \mathrm{MSE}=42586$, $p<0.001$. Where the mean reaction time of the young was $583 \mathrm{~ms}(S D=197)$, the elderly participants' average response delay was $768 \mathrm{~ms}(S D=209)$. However, no effects were found of modality $(F=1.56)$ and variability $(F<1)$, which is not in line with the SCL data. All interactions were non-significant $(F \mathrm{~s}<1)$. Again, this indicates that there was neither a combined effect of modality and variability, nor a disproportionate beneficial effect in the elderly participants.

\section{Transfer performance}

The ANOVA yielded a significant effect of age group, $F(1,72)=48.85$, MSE $=0.04$, $p<0.001$. On the average, the young participants solved $85 \%$ of the test problems 

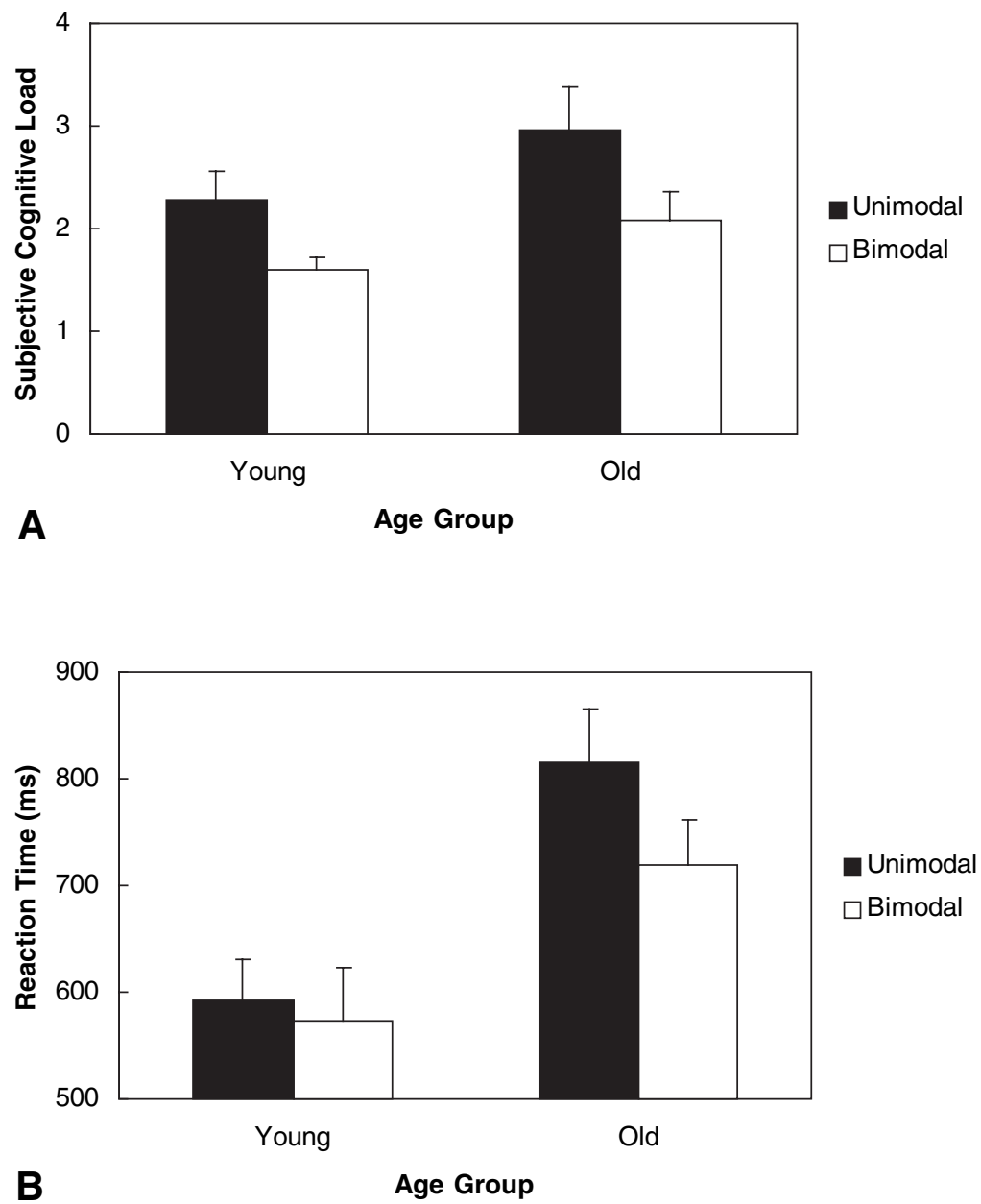

Figure 2. Cognitive load measures: In Panel A subjective cognitive load (SCL) is depicted as a function of age group and modality. Panel B shows reaction time (ms) on the secondary task as a function of age group and modality. Error bars indicate one standard error of the mean

$(S D=16 \%)$, whereas the elderly participants solved $54 \%(S D=23 \%)$. No main effect of modality was found $(F<1)$. Interestingly, however, the main effect of variability approached significance, $F(1,72)=2.93, p=0.09$, where performance was higher in the random than in the blocked condition. Although this effect seems stronger for the elderly than for the young participants ( $\pm 10 \%$ and $5 \%$ improvement, respectively; see Figure 3 ), no significant age group by variability interaction was found $(F<1)$.

\section{DISCUSSION}

On the basis of CLT (Sweller et al., 1998) and Baddeley's (1992) model of working memory, it was hypothesized that bimodally presented worked examples lead to lower levels of cognitive load and higher levels of performance than unimodally presented 


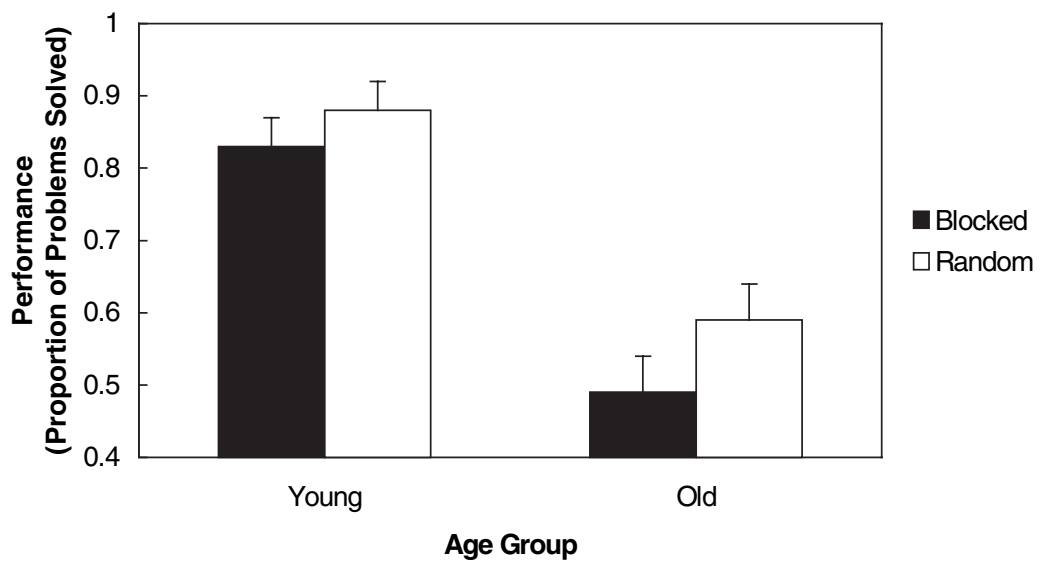

Figure 3. Performance (proportion of problems solved) as a function of age group and variability. Error bars indicate one standard error of the mean

worked examples. Furthermore, worked examples presented in a random order were expected to lead to a higher level of cognitive load, but also a higher level of performance than worked examples presented in a blocked format. A combined effect of randomly presented, bimodal worked examples was expected in that a high level of cognitive load leads to relatively high levels of performance. Finally, it was hypothesized that these beneficial effects are relatively strong in the elderly.

The older participants experienced higher levels of SCL than their young counterparts. Moreover, the elderly were slower on the secondary task. Remarkably, both the young and the older participants reported rather low levels of SCL in all conditions. This may be due to a negative response bias. Nevertheless, the subjective SCL turned out to be sensitive to modality. That is, SCL was higher in the unimodal than in the bimodal condition. Although statistically insignificant, the same pattern was found for the reaction times (see Figure 2). The effects did not interact with age group, however. That is, contrary to the hypothesis, the elderly participants did not take more advantage of the bimodal condition than the young participants.

Interestingly, there was a nearly significant performance effect of training variability. That is, in the random condition performance was higher than in the blocked condition. Considering Figure 3, it seems that the performance effect is largely attributable to the elderly participants. This observation was not confirmed by a significant interaction between age group and training variability, however. Nevertheless, main effect suggests that a random arrangement of training problems leads to more elaborate processing and thus to higher transfer performance in both age groups.

According to CLT, enhanced performance should have been the result of a relatively high level of germane cognitive load in the training phase. However, the absence of a main effect of variability and an interaction between variability and modality with respect to both SCL and reaction time did not support this hypothesis.

What do we learn from the present results? Obviously, the data do not demonstrate any disproportionate benefits of CLT-based instructional formats for elderly learners, as was established by van Gerven (2002) and van Gerven et al. (2000, 2003). Nevertheless, this study has revealed new findings in the light of CLT, which encourage further explorations. First, there is the tendency of both young and elderly adults to perform better in the random than in the blocked training condition. This is important, because performance effects 
induced by a CLT-based training format have not been found earlier with elderly participants (see van Gerven, 2002; van Gerven et al., 2003). Second, there is a clear effect of modality with respect to SCL. If this low rating was not due to a response bias, then germane cognitive load can be raised even more. This may be achieved by not only manipulating the variability, but also the complexity of the worked examples. This could also lead to overload, however. Therefore, the level of germane load should be adjusted to the capacity of the learner, for instance, by selecting training problems on the basis of measured levels of cognitive load (see Camp, Paas, Rikers, \& van Merriënboer, 2001).

Thus, future research on CLT and aging should have two main objectives. First, it should be aimed at optimizing the level of germane cognitive load. Second, it should replicate the interaction between age group and training condition, which was found in earlier research. CLT would have the strongest case if this interaction was not only found for cognitive load, but also for transfer performance.

To conclude, this study revealed that the beneficial effects of training modality and variability are similar across age groups. Although this is not in line with the hypothesis that the elderly benefit more from the CLT-based conditions than the young, it is an important outcome. First, it emphasizes that although the elderly perform at a lower level than the young, they are equally able to improve that performance level under the right conditions. Second, it encourages further explorations of how to lift the elderly's performance level towards that of the young. Both implications fit today's pursuit of lifelong learning.

\section{ACKNOWLEDGEMENTS}

We are grateful to Marcel Hendrickx, Johan Gielissen, and Ron Hellenbrand for their technical support. Furthermore, we thank Marieke Werrij for recording the narrations and Marijn Bruinink for testing the participants.

\section{REFERENCES}

Baddeley, A. D. (1992). Working memory. Science, 255, 556-559.

Battig, W. F. (1972). Intratask interference as a source of facilitation in transfer and retention. In R. F. Thompson, \& J. F. Voss (Eds.), Topics in learning and performance (pp. 131-159). New York: Academic Press.

Camp, G., Paas, F., Rikers, R., \& van Merriënboer, J. J. G. (2001). Dynamic problem selection in air traffic control training: a comparison between performance, mental effort, and mental efficiency. Computers in Human Behavior, 17, 575-595.

Chandler, P., \& Sweller, J. (1996). Cognitive load while learning to use a computer program. Applied Cognitive Psychology, 10, 151-170.

Constantinidou, F., \& Baker, S. (2002). Stimulus modality and verbal learning performance in normal aging. Brain and Language, 82, 296-311.

De Croock, M. B. M., van Merriënboer, J. J. G., \& Paas, F. (1998). High versus low contextual interference in simulation-based training of troubleshooting skills: effects on transfer performance and invested mental effort. Computers in Human Behavior, 14, 249-267.

Hasher, L., \& Zacks, R. T. (1988). Working memory, comprehension, and aging: a review and a new view. In G. H. Bower (Ed.), The psychology of learning and motivation: Advances in research and theory (Vol. 22, pp. 193-225). San Diego: Academic Press.

Jamieson, B. A., \& Rogers, W. A. (2000). Age-related effects of blocked and random practice schedules on learning a new technology. Journal of Gerontology: Psychological Sciences, 55B, P343-P353. 
Kalyuga, S., Chandler, P., \& Sweller, J. (2000). Incorporating learner experience into the design of multimedia instruction. Journal of Educational Psychology, 92, 126-136.

Luchins, A. S. (1942). Mechanization in problem solving: the effect of Einstellung. Psychological Monographs, 54, Whole No. 248.

Luteijn, F., \& Van der Ploeg, F. A. E. (1983). Groninger intelligentie test: Handleiding [Groningen intelligence test: Manual]. Lisse, The Netherlands: Swets \& Zeitlinger.

Marcus, N., Cooper, M., \& Sweller, J. (1996). Understanding instructions. Journal of Educational Psychology, 88, 49-63.

Mayr, U., Kliegl, R., \& Krampe, R. T. (1996). Sequential and coordinative processing dynamics in figural transformations across the life span. Cognition, 59, 61-90.

Moreno, R., \& Mayer, R. E. (1999). Cognitive principles of multimedia learning: the role of modality and contiguity. Journal of Educational Psychology, 91, 358-368.

Olina, Z., Reiser, R., Huang, X., Lim, J., \& Park, S. (2006). Problem format and presentation sequence: effects on learning and mental effort among US high school students. Applied Cognitive Psychology, 20, 299-309 (this issue).

Paas, F. (1992). Training strategies for attaining transfer of problem-solving skill in statistics: a cognitive-load approach. Journal of Educational Psychology, 84, 429-434.

Paas, F., Camp, G., \& Rikers, R. (2001). Instructional compensation for age-related cognitive declines: effects of goal specificity in maze learning. Journal of Educational Psychology, 93, 181186.

Paas, F., Tuovinen, J., Tabbers, H., \& van Gerven, P. W. M. (2003). Cognitive load measurement as a means to advance cognitive load theory. Educational Psychologist, 38, 63-71.

Paas, F., \& van Merriënboer, J. J. G. (1994a). Instructional control of cognitive load in the training of complex cognitive tasks. Educational Psychology Review, 6, 351-371.

Paas, F., \& van Merriënboer, J. J. G. (1994b). Variability of worked examples and transfer of geometrical problem solving skills: a cognitive-load approach. Journal of Educational Psychology, 86, 122-133.

Paas, F., van Merriënboer, J. J. G., \& Adam, J. J. (1994). Measurement of cognitive load in instructional research. Perceptual and Motor Skills, 79, 419-430.

Renkl, A., Stark, R., Gruber, H., \& Mandl, H. (1998). Learning from worked-out examples: the effects of example variability and elicited self-explanations. Contemporary Educational Psychology, 23, 90-108.

Salthouse, T. A. (1996). The processing-speed theory of adult age differences in cognition. Psychological Review, 103, 403-428.

Salthouse, T. A., \& Babcock, R. L. (1991). Decomposing adult age differences in working memory. Developmental Psychology, 27, 763-776.

Salthouse, T. A., Fristoe, N., McGuthry, K. E., \& Hambrick, D. Z. (1998). Relation of task switching to speed, age, and fluid intelligence. Psychology and Aging, 13, 445-461.

Sweller, J. (1988). Cognitive load during problem solving: effects on learning. Cognitive Science, 12, $257-285$.

Sweller, J., van Merriënboer, J. J. G., \& Paas, F. (1998). Cognitive architecture and instructional design. Educational Psychology Review, 10, 251-296.

Tabbers, H. K., Martens, R. L., \& van Merriënboer, J. J. G. (2004). Multimedia instructions and cognitive load theory: effects of modality and cueing. British Journal of Educational Psychology, $74,71-81$.

Tindall-Ford, S., Chandler, P., \& Sweller, J. (1997). When two sensory modes are better than one. Journal of Experimental Psychology: Applied, 3, 257-287.

van Gerven, P. W. M. (2002). Efficient complex skill training into old age: Exploring the benefits of cognitive load theory. Unpublished doctoral dissertation, The Netherlands: Maastricht University.

van Gerven, P. W. M., Paas, F., van Merriënboer, J. J. G., Hendriks, M., \& Schmidt, H. G. (2003). The efficiency of multimedia training into old age. British Journal of Educational Psychology, 73, 489-505.

van Gerven, P. W. M., Paas, F., van Merriënboer, J. J. G., \& Schmidt, H. G. (2000). Cognitive load theory and the acquisition of complex cognitive skills in the elderly: towards an integrative framework. Educational Gerontology, 26, 503-521.

van Merriënboer, J. J. G., Schuurman, J. G., De Croock, M. B. M., \& Paas, F. (2002). Redirecting learners' attention during training: effects on cognitive load, transfer test performance, and training efficiency. Learning and Instruction, 12, 11-37.

van Merriënboer, J. J. G., \& Sweller, J. (2005). Cognitive load theory and complex learning: recent developments and future directions. Educational Psychology Review, 17, 147-177. 